\title{
Prevalence of major skin diseases of cattle in and around Hawassa, Southern Ethiopia
}

\author{
Addise Ambilo ${ }^{1}$ and Abriham Kebede ${ }^{2 *}$ \\ ${ }^{1}$ School of Veterinary Medicine, University of Gonder, Ethiopia \\ ${ }^{2}$ School of Veterinary Medicine, Wollege University, Ethiopia
}

*Corresponding author: Abriham Kebede, School of Veterinary Medicine, College of Medical and Health Science, Wollega University, P.O. Box: 395, Nekemte, Ethiopia.

To Cite This Article: Abriham Kebede. Prevalence of major skin diseases of cattle in and around Hawassa, Southern Ethiopia. Am J Biomed Sci \& Res. 2019 - 2(3). AJBSR.MS.ID.000586. DOI: 10.34297/AJBSR.2019.02.000586

Received: April 03, 2019 | Published: April 09, 2019

\begin{abstract}
A cross-sectional study was conducted to determine the prevalence of major skin diseases of cattle in and around Hawassa from November 2011 to April 2012. Of the total 384 cattle examined, 66 (17.27\%) were clinically infected with different skin diseases of various etiologic origin. The most commonly encountered skin diseases were: dermatophytosis (8.32\%), ascariasis (3.13\%), pediculosis (2.60\%), lumpy skin disease $(1.62 \%)$ and dermatophilosis $(1.56 \%)$. No significant differences $(\mathrm{P}>0.05)$ were observed among age, breed and managemental groups in relation to the prevalence of dermatophilosis and lumpy skin disease infection rates whereas significantly $(\mathrm{P}<0.05)$ higher cases of dermatophytosis and pediculosis were recorded in animals less than two years of age.
\end{abstract}

In dermatophytosis and pediculosis cases, no significant difference $(\mathrm{P}>0.05)$ was seen between the sex and breed groups. In pediculosis cases, the major lice species encountered were Bovicolabovis, Haematopinus and Linognatus species. Statistically significant $(\mathrm{p}<0.05)$ difference was observed in two sex groups regarding to ascariasis infestations. The frequent sites of ringworm lesions were on the hump, sacral areas, face and base of the horn, ears and sides of the body. Hides and skins are main sources of raw materials for tannery industry inputs. Therefore, animal health assistants, veterinarians, regional governments and tanneries should support activities in fight of skin diseases.

Keywords: Cattle, Hawassa, Prevalence, Skin Diseases

\section{Introduction}

Ethiopia with an area of 1.2 million square kilometres $\left(\mathrm{km}^{2}\right)$ has huge livestock population having 44,318,877 cattle, 23,619,720 sheep and 23,325 goats [1]. These animals provide draught power, milk, meat, fibber, fuel and fertilizer and they also provide hide and skin which partially processed for export or tanned and finished in the country's tanning shoe making and leather goods industries [2].

The development of leather industry requires great quantity of raw materials of various origins, the principal source of which is livestock industry [3]. Although livestock production and tanning industries of the world are increasing in number, the source of the material for the tanning industry is limited both in quantity and quality [4]. Ethiopia produces about 2.7 million of hide, 8.1 million of sheep skin and 7.5 million of goat skin per annum for tannery industry and is the leading export item of the country next to coffee with its finished or semi-finished leather products $[5,6]$. During past decades leather and semi processed hides and skins have constituted the second major export product of country with 10 to $20 \%$ of total of foreign earnings [7].

Although the of number of tanneries involved in production of finished and semi-finished leather products are increasing from time to time, the sector and the country are losing revenue due to a decline in leather quality and fall in export prices [8]. Of the total skin processed at tanneries, one fourth to one third of it is unsuitable for export due to various defects, $65 \%$ of which occur in pre-slaughter defects stage [4]. A considerable portion of these pre-slaughter defects are directly related to skin diseases or secondary damage that occurs when the animal scratches itself to relieve the itching associated with some of these diseases [8]. The most common cattle skin diseases reported in Ethiopia are: dermatophilosis, lumpy skin disease (LSD), dermatophytosis, dediculosis, dcariasis, photosensitivity and warts $[9,10]$.

Besides their impact on leather quality, skin diseases impose economic losses as result of reduction in body weight gain and milk yield, occasional mortality, reduction of performance in draft animals and losses associated with treatment and prevention of diseases [11]. In addition, some skin diseases have zoonotic significance [12]. The potential economic loss the country is experiencing necessitates the nation-wide detailed investigation on the distribution of important skin diseases and their determinants. Therefore, the objectives of this study were: to determine the prevalence of major skin diseases of cattle in and around Hawassa, Southern 
Ethiopia and to assess the relation among different factors with the occurrence of major skin diseases of cattle in the area.

\section{Material and Methods}

\section{Study area}

The study was conducted in and around Hawassa town, the capital city of southern Nations Nationalities and People Regional state from November 2011 to April 2012. Hawassa is in Rift valley at about $275 \mathrm{~km}$ South of Addis Ababa. Geographically, it lies between $4^{0} 27^{\prime}$ and $8^{\circ} 30^{\prime}$ North latitude and $34^{\circ} 21^{\prime}$ and $39^{\circ} 1^{\prime}$ East longitude. The town has an estimated human population of 150,000 with an area of $50 \mathrm{~km}$ and altitude range from 1,500-2,000 metre above sea level. The agro-climatic condition is temperate climate (Woynadega). The area has an average annual rainfall of $997.6 \mathrm{~mm}$ and the maximum and minimum annual temperature is estimated to be around $17^{\circ} \mathrm{C}$ and $24^{\circ} \mathrm{C}$ respectively. In addition, the town has got an estimated 1,573,318 cattle,183,464 goats,221,505 sheep,49,150 horses,48,653 asses and1,196,504 poultry livestock population [13]. Hawassa town has one government veterinary clinic and School of Veterinary Medicine at Hawassa University providing the veterinary service.

\section{Study animals}

The study animals were cattle in and surrounding Hawassa and it includes sexes, breeds and all age group weather they are from intensive and extensive farming system. The age of the animals were determined primarily based on the information obtained from the animal owners and also by looking to the dentition pattern of animals [5].

\section{Study Design and Sample size determination}

A cross-sectional study was conducted to determine the current prevalence of major skin diseases in the study area. The total numbers of animals required for the study was calculated based on the formula given by Thrusfield M [26]. Since there was no previous study in the prevalence of skin diseases in the area, 50\% prevalence was taken to calculate the sample size and it was calculated at $95 \%$ confidence interval and a desired accuracy level of 5\% using the following formula:

$$
n=\frac{(1.96)^{2} P \exp (1-\text { Pexe })}{d^{2}}
$$

Where: $\mathrm{n}=$ required sample size, $\mathrm{p}_{\exp }=$ expected prevalence and $\mathrm{d}=$ desired level of precision

Therefore, the calculated sample size was 384 and these animals were selected randomly.

Results

\section{Overall prevalence}

Table 1: Association of risk factors with major skin diseases.

\begin{tabular}{|c|c|c|c|c|c|c|}
\hline \multirow{3}{*}{ Factors } & Categories & No. examined & No. Positive & Prevalence (\%) & Chi-square & P-value \\
\hline \multirow{3}{*}{ Breed } & Cross & 38 & 9 & 23.68 & 1.25 \\
\cline { 2 - 7 } & Local & 346 & 57 & 16.47 & 0.26 \\
\cline { 2 - 7 } & Total & 384 & 66 & 17.19 & \\
\hline
\end{tabular}

\section{Study methodology}

\section{Clinical examination}

In this study, animals were selected during sample collections and the related risk factors such as sex, age, breed and managemental conditions were recorded before sampling from the animal. The tags of study animals were properly recoded during sampling and then each animal was also carefully inspected for the skin pathogens. All the encountered cases were taken to Hawassa university laboratory for identification of skin pathogens.

Clinical skin disease investigation was conducted by examination of skin of each animal and through visual inspection and palpation. For positive cases on clinical examination, detailed husbandry and health history was taken from the owner of the animals. Depending upon the clinical presentation of skin diseases, samples such as, skin-scrapings, hair specimens, pustules, abscesses and externally visible parasites were collected and subjected to a proper laboratory investigation for confirmation. Lumpy skin disease was diagnosed tentatively based on clinical findings.

\section{Laboratory investigation}

Specimen of hair plus skin were plucked from lesions suspected of dermatophytosis using forceps, put in dry Petri dish and transported to the laboratory to demonstrate characteristic fungal elements in a wet mount of lesion scraping [12]. Deep scrapings of pustules and abscess were collected from demodicosis suspected cases and squash smears of their content were examined for the presence of demodectic mites at 10x magnification of light microscope [12]. For the mange infestations, skin scrapings (till capillary blood oozes) were taken from the periphery of active lesions. The specimen was placed in test tubes and treated by $10 \mathrm{ml} \mathrm{KOH} \mathrm{(10 \% )}$ and examined based on the standard procedures [24]. Exudative crusts were taken by pairs of forceps and transported to the laboratory in dry Petri dish where they are subjected to giemsa staining for demonstration of Dermatophilus congolensis. Lice were collected in $70 \%$ alcohol by parting the hair and were identified using the standard procedures [12].

\section{Data management and analysis}

Data were collected and recorded on specially designed form (Annex) and preliminary analysis was done in Microsoft excel. The laboratory data were coded and the association of risk factors with the occurrence of the diseases were assessed using chi-square. All statistical analyses were conducted using SPSS 22 statistical software and $P<0.05$ was taken as statistically significant in all cases. 


\begin{tabular}{|c|c|c|c|c|c|c|}
\hline \multirow{3}{*}{ Sex } & Male & 123 & 26 & 21.14 & 1.98 \\
\cline { 2 - 6 } & Female & 261 & 40 & 15.33 & 0.15 \\
\cline { 2 - 7 } & Total & 384 & 66 & 17.19 & 25.57 \\
\hline \multirow{3}{*}{ Age } & $<2$ years & 93 & 32 & 34.41 & 0 \\
\cline { 2 - 7 } & $\geq 2$ years & 291 & 34 & 11.68 & 7.26 \\
\cline { 2 - 7 } & Total & 384 & 66 & 17.19 & 0.007 \\
\cline { 2 - 7 } & Poor & 247 & 52 & 21.05 & \\
\hline
\end{tabular}

Of the total of 384 cattle examined, $66(17.27 \%)$ were affected by skin diseases of various etiological agent. Although relatively higher percentages of the skin diseases were observed in cross breed cattle $(23.68 \%)$ and male animals $(21.13 \%)$ the difference was not statistically significant. On the other hand, the overall prevalence of major skin diseases was significantly $(P<0.05)$ higher in animals less than two years of age and in poor husbandry system (Table 1).

\section{Ascariasis}

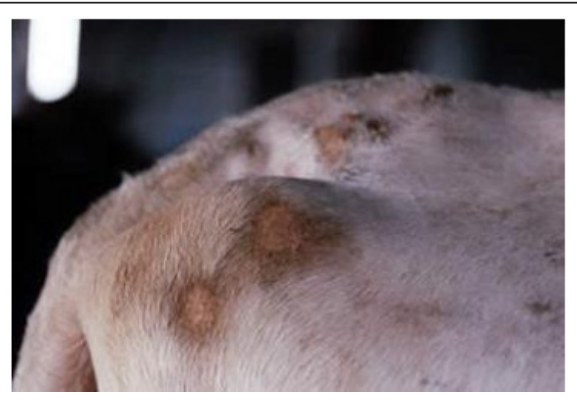

Figure 1: Demodex lesion in cattle.

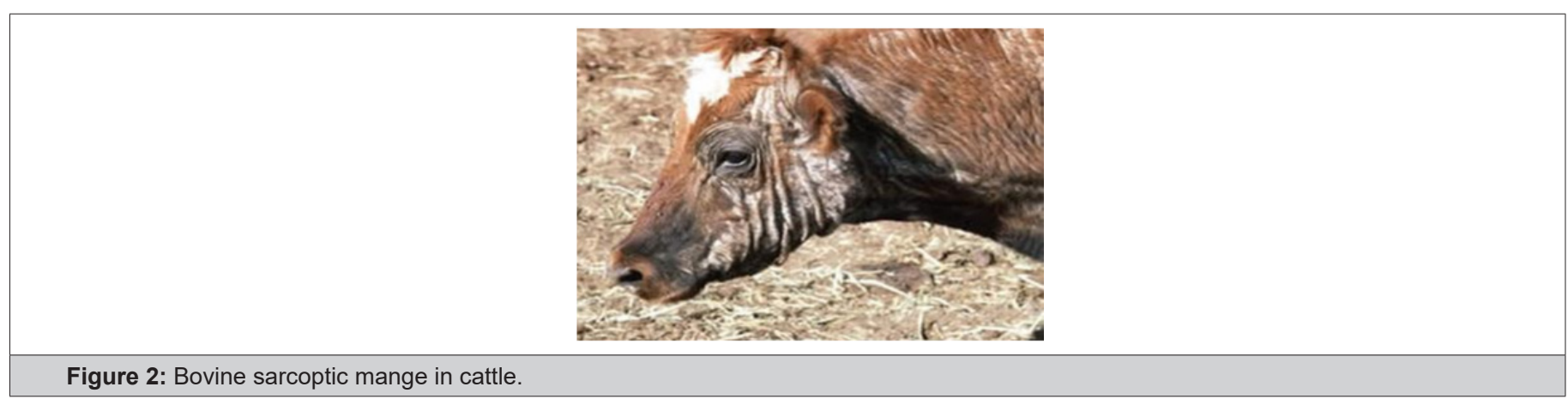

Table 2: Prevalence of Ascariasis in cattle in relation to different risk factors.

\begin{tabular}{|c|c|c|c|c|c|}
\hline Factors & Categories & No. examined & No. Positive & Prevalence (\%) & P-value \\
\hline \multirow{3}{*}{ Breed } & Local & 346 & 12 & 3.47 & \\
\hline & Cross & 38 & 0 & 0 & \\
\hline & Total & 384 & 12 & 3.13 & \\
\hline \multirow{3}{*}{ Sex } & Male & 123 & 9 & 7.32 & \multirow{3}{*}{0} \\
\hline & Female & 261 & 3 & 1.15 & \\
\hline & Total & 384 & 12 & 3.13 & \\
\hline \multirow{3}{*}{ Age } & $<2$ years & 93 & 3 & 3.23 & \multirow{3}{*}{0.58} \\
\hline & $\geq 2$ years & 291 & 9 & 3.09 & \\
\hline & Total & 384 & 12 & 3.13 & \\
\hline \multirow{3}{*}{ Husbandry } & Poor & 247 & 11 & 4.45 & \multirow{3}{*}{0.03} \\
\hline & Good & 137 & 1 & 0.72 & \\
\hline & Total & 384 & 12 & 3.13 & \\
\hline
\end{tabular}


Ascariasis is a term for a rash, caused by mites, sometimes with a papillae (pruritic dermatitis) or papule (popular urticaria), and usually accompanied by a hive (urticaria) and severe itching sensations. Of the total of 384 cattle examined, $3.13 \%$ were positive for ascariasis. The prevalence was $3.47 \%$ in local, but the disease was not observed in cross breed animals. Male animals $(7.31 \%)$ were more significantly $(P<0.05)$ affected than females $(1.15 \%)$. No significant difference $(P>0.05)$ was observed in two age groups. The major mange mites encountered were Demodex (2.08\%) and Sarcoptes (1.04\%). Gross lesions of demodectic cases were pustular nodules distributed over the neck, shoulder and dewlap areas (figure 1) and deep scrapings of the lesion prevailed grayish pus. Demodex spp are unique among parasitic mites, because they are elongated with short, stumpy legs. Sarcoptes are typically found on parts of the body with less hair such as the hock, elbow or muzzle (Figure 2). In skin scrapings, adults sarcoptes was readily recognized by their slender, elongated bodies, oval, ventrally flattened and dorsally convex tortoise-like bodies and multiple cuticular spines under microscope (Table 2).

\section{Dermatophilosis}

Of the total of 384 cattle examined, $1.56 \%$ was positive for dermatophilosis. Although the higher prevalence of dermatophilosis was observed in cross breed cattle (5.26\%), the difference was not statistically significant $(P>0.05)$. Statistically significant $(P>0.05)$ associations were also not observed with other risk factors (Table $3)$.

\begin{tabular}{|c|c|c|c|c|c|}
\hline Factors & Categories & No. examined & No. positive & Prevalence (\%) & P-value \\
\hline \multirow{3}{*}{ Breed } & Local & 346 & 4 & 1.16 & \multirow{3}{*}{0.11} \\
\hline & Cross & 38 & 2 & 5.26 & \\
\hline & Total & 384 & 6 & 1.56 & \\
\hline \multirow{3}{*}{ Sex } & Male & 123 & 1 & 0.81 & \multirow{3}{*}{0.66} \\
\hline & Female & 261 & 5 & 1.91 & \\
\hline & Total & 384 & 6 & 1.56 & \\
\hline \multirow{3}{*}{ Age } & $<2$ years & 123 & 2 & 1.63 & \multirow{3}{*}{1} \\
\hline & $\geq 2$ years & 261 & 4 & 1.53 & \\
\hline & Total & 384 & 6 & 1.56 & \\
\hline \multirow{3}{*}{ Husbandry } & Poor & 247 & 4 & 1.62 & \multirow{3}{*}{1} \\
\hline & Good & 137 & 2 & 1.46 & \\
\hline & Total & 384 & 6 & 1.56 & \\
\hline
\end{tabular}

\section{Dermatophytosis}

\begin{tabular}{|c|c|c|c|c|c|}
\hline Factors & Categories & No. examined & No. Positive & Prevalence (\%) & $P$ value \\
\hline \multirow{3}{*}{ Breed } & Local & 346 & 28 & 8.09 & \multirow{3}{*}{0.54} \\
\hline & Cross & 38 & 4 & 10.53 & \\
\hline & Total & 384 & 32 & 8.33 & \\
\hline \multirow{3}{*}{ Sex } & Male & 123 & 12 & 9.76 & \multirow{3}{*}{0.48} \\
\hline & Female & 261 & 20 & 7.66 & \\
\hline & Total & 384 & 32 & 8.33 & \\
\hline \multirow{3}{*}{ Age } & $<2$ years & 93 & 24 & 25.81 & \multirow{3}{*}{0} \\
\hline & $\geq 2$ years & 291 & 8 & 2.75 & \\
\hline & Total & 384 & 32 & 8.33 & \\
\hline \multirow{3}{*}{ Management } & Poor & 247 & 25 & 10.12 & \multirow{3}{*}{0.08} \\
\hline & Good & 137 & 7 & 5.11 & \\
\hline & Total & 384 & 32 & 8.33 & \\
\hline
\end{tabular}

Out of the 66 cases diagnosed, 32 (8.32\%) of the animals were having generalized and widespread lesion all over the body. Significantly higher $(P<0.05)$ prevalence rate was encountered on animals less than two (25.8\%) than those greater or equal to two years of age. Statistically significant associations $(P>0.05)$ were not observed with other risk factors (Table 4 ). The frequently affected areas of the body were hump, sides of body, sacrum, face, neck, and shoulder.

\section{Lumpy skin disease}

Of the total of 384 cattle examined, 6 (1.56\%) animals were clinically positive for lumpy skin disease. The prevalence was 
$1.73 \%$ in local breeds, but it was not observed in cross breed animals. There was no significant difference $(p>0.05)$ in prevalence rate of lumpy skin disease among the age, sex, breed groups and husbandry systems (Table 5). Affected animals had painful nodular skin lesions diffused all over the body including the conjunctiva and rectum, swollen leg, and dewlap areas, enlarged superficial lymph nodes and their body temperature varied from 39.5 to $41^{\circ} \mathrm{C}$.

\begin{tabular}{|c|c|c|c|c|c|}
\hline Factors & Categories & No. examined & No. positive & Prevalence (\%) & P-value \\
\hline \multirow{3}{*}{ Breed } & Local & 346 & 6 & 1.73 & \\
\hline & Cross & 38 & 0 & 0 & \\
\hline & Total & 384 & 6 & 1.56 & \\
\hline \multirow{3}{*}{ Sex } & Male & 123 & 1 & 0.81 & \multirow{3}{*}{0.66} \\
\hline & Female & 261 & 5 & 1.92 & \\
\hline & Total & 384 & 6 & 1.56 & \\
\hline \multirow{3}{*}{ Age } & $<2$ years & 93 & 1 & 1.07 & \multirow{3}{*}{1} \\
\hline & $\geq 2$ years & 291 & 5 & 1.72 & \\
\hline & Total & 384 & 6 & 1.56 & \\
\hline \multirow{3}{*}{ Husbandry } & Poor & 247 & 5 & 2.02 & \multirow{3}{*}{0.42} \\
\hline & Good & 137 & 1 & 0.73 & \\
\hline & Total & 384 & 6 & 1.56 & \\
\hline
\end{tabular}

\section{Pediculosis}

Pediculosis is an infestation of the hairy parts of the body or clothing with the eggs, larvae or adults of lice. Of the total of 384 cattle examined, $10(2.60 \%)$ were positive for different species of lice. The major lice species observed were Bovicola bovis, Linognathus species and Haematopinus species. B. bovis louse was a reddish-brown in colour with dark transverse bands on the abdomen. The head is relatively large, as wide as the body and is rounded anteriorly, with the mouthparts adapted for chewing. The legs are slender and for moving amongst the hair, with small claws, on each leg. Linognathus species was long-nosed clouse with an elongated, pointed head and body. Haematopinus species was broad in shape with a short, pointed head and short-nosed louse. Pediculosis in cattle occurs throughout the world and is more common in cattle than in any other domestic animal. Louse populations are highest in cattle during the winter months and heavy infestations cause irritation, leading to rubbing against feed barriers. This results in hair loss over the neck and shoulders and reduced daily weight gain. The prevalence was higher in cross breed animals (7.89\%) than local breed animals (2.02\%), but not statistically significant difference. It was significantly $(P<0.05)$ higher in animals with age less than two years $(32.60 \%)$ than greater than or equal to two. Significant variation was not observed in sex groups and husbandry systems (Table 6).

\begin{tabular}{|c|c|c|c|c|c|}
\hline Factors & Categories & No. examined & No. Positive & Prevalence (\%) & P-value \\
\hline \multirow{3}{*}{ Breed } & Local & 346 & 7 & 2.02 & \multirow{3}{*}{0.06} \\
\hline & Cross & 38 & 3 & 7.89 & \\
\hline & Total & 384 & 10 & 2.6 & \\
\hline \multirow{3}{*}{ Sex } & Male & 123 & 3 & 2.44 & \multirow{3}{*}{1} \\
\hline & Female & 261 & 7 & 2.68 & \\
\hline & Total & 384 & 10 & 2.6 & \\
\hline \multirow{3}{*}{ Age } & $<2$ years & 93 & 3 & 3.23 & \multirow{3}{*}{0.007} \\
\hline & $\geq 2$ years & 291 & 7 & 2.41 & \\
\hline & Total & 384 & 10 & 2.6 & \\
\hline \multirow{3}{*}{ Husbandry } & Poor & 247 & 7 & 2.83 & \multirow{3}{*}{1} \\
\hline & Good & 137 & 3 & 2.19 & \\
\hline & Total & 384 & 10 & 2.6 & \\
\hline
\end{tabular}

\section{Discussion}

Among the different skin diseases, dermatophytosis ranked to be the first among the different clinical cases encountered in southern Ethiopia. It is the most important complaints of animal owners regarding skin diseases of cattle in the area. Although no detailed investigation was made to identify the type of fungal infection associated with skin disease, nearly $8.32 \%$ of the animals in and around Hawassa were shown to suffer from dermatophytosis. Due largely to the fact that it is not a reportable disease; the incidence of ring worm in animals is not precisely known [13]. Dermatophytosis in 
domestic animals is an infection of keratinized tissues by one of the two generals of fungi, Microsporum and Trichophyton [12,14]. In developed countries, it has the greatest economic and human health consequence [9]. But in Ethiopia, little attention was given to the economic and zoonotic risk assessment of the disease.

Although no detailed investigation was under taken in order to identify the major dermatophytid species of animals involved, ringworm infection is the common hospital presentation, especially in HIV infected patients. Most of the animal owners mentioned ringworm as the major skin disease of cattle in the area. However, this clinical manifestation and the naming of the disease might not be as such specific to fungal infection. Young animals are more susceptible to dermatophytosis than adults [17]. In the present study too, the prevalence of disease was significantly $(p<0.05)$ higher in animals less than two year of age than the adult age group. Of all dermatophytid cases, 32 (8.32\%) of them have generalized and widespread lesions, 24 (25.8\%) of which were seen on younger animals. This is because, dermatophytosis in adult and healthy animal is self-limiting but in young and debilitated animals the infection is wide spread and persistent [16].

The most usual route of infections is by penetration of intact skin or more commonly of skin subjected to minor trauma by rubbing, scratching or prolonged moistening [17]. In the present study also the frequently affected area was found to the hump and sacrum, but in generalized cases, especially in younger animals, the dorsum and sides of the body were the usual sites of the diffused lesions. This could be due to the nursing behaviour of the dam, which could distribute the infection of over the body while nursing.

Because of the endemicity of the disease in the area, most of the animal owners are familiar with its growth, gross pathological lesion and the age group affected. Most complaints did not practiced isolation of the sick animals from the healthy once in their normal husbandry practice. This practice will undoubtedly contribute to easy transmission of the disease within herd because of the highly contagious nature of the disease [17].

In Ethiopia, outbreaks of LSD have been reported at different times in western part of the country since 1981 [18] similar studies conducted in Woliso and southern rangeland revealed $27.9 \%$ and $11.6 \%$ prevalence, respectively, indicating the widespread importance the disease since its recognition in 1957 in East Africa [19].

In agreement with previous report of $[12,14]$, two age groups, breeds and both sexes in the present study area were found to be equally susceptible to lumpy skin disease infection. The maximum morbidity rate was found to be in the month of December followed by November similar peak of out breaks was obtained during the months of November and December in central part of the country [19]. This might be associated with higher activity of insect vectors $[12,14]$. Most of clinical presentations like cutaneous lesions, lacrimation's, swelling of the leg and dewlap areas, swelling of the peripheral lymph nodes, decreased milk yield and occasional mortalities are symptoms regularly observed by many authors $[12,14,16]$.

Despite no complaints made by the animal owners, $2.60 \%$ of the animals were infested with different lice species at various infestation levels. Usually mild cases are not considered as being having any pathogenic effect, but heavy infestations are associated with extensive hide damage (Habte, 1994). The common lice species identified were B. bovis, Linognathus and Haematopinus species. All age groups of cattle can be infested with lice, but the heaviest infestation is usually are seen on calves, yearlings or in older unthrifty animals and those animals living in poor management. In support of other observation $[20,21]$, young animals were severely affected than adult animals, this is perhaps because they possess a higher ratio of accessible surface to body volume, inefficient grooming behaviour and other defence capabilities [21].

Demodex is the normal flora of bovine skin and is the most prevalent of all manage infestation [25]. In line with this; the present study has shown prevalence rate of $3.13 \%$ for Demodex bovis and Sarcoptes scabies var bovis. Demodicosis will not draw attention unless closely inspected and palpated [16]. In support of this statement, almost all the cases were not recognized by the owners of the animals. The prevalence rate manage mite obtained in this study $(3.13 \%)$ is by far lower than other works done in different parts of the country $7.4 \%$ [9] and 28\% [22]. This might be due to the differences in management, climatic condition, and study design and time factor.

Dermatophilosis is the least prevalent skin disease in the study area, i.e. $1.56 \%$ which is lower than the previous report, $16.3 \%$ [9] and $15.04 \%$ [23]. This might be due to low level of rainfall in the study period, which could prohibit clinical streptotrichosis from coming to picture. Prolonged wetting, high humidity and various ectoparasites which reduce or permeate the natural barriers of the integument influence the development, prevalence, seasonal incidence and transmission of dermatophilosis [16].

\section{Conclusion and recommendations}

Skin diseases cause different problems in the cattle with decreasing production, reproduction, skin and hide quality. The most common cattle skin diseases reported in Ethiopia are: dermatophytosis, dermatophilosis, lumpy skin disease, ascariasis, photosensitivity, wart and pediculosis. Apart their impact on leather quality, skin diseases impose economic losses as result of rededication in of performance in draft animals and losses associated with treatment and prevention of the diseases. Some skin diseases such as ring worm also has zoonotic health significance most skin diseases are left undiagnosed under the shadow of the other infections and parasitic diseases, with added zoonotic importance of some of the mentioned skin diseases, all undoubtedly reduce the quality of raw materials for tanneries with this consideration, the following recommendations are forwarded.

a. Further investigation should be under to identify the Dermatophytid species-affecting cattle to assess its zoonotic risk.

b. Animal owners, veterinarians and animal health assistants should give attention for those highly susceptible animals and trying to manage animals at good conditions as much as possible.

c. Veterinarians and animal health assistants should give more focus to skin diseases at clinical presentation and regional gov- 
ernments and tanneries should support activities in fight of skin diseases.

\section{References}

1. Abadi Y (2000) Current problem of leather industry. In: RC Merkel, G Abebe, AL Goetsch (Eds). The opportunities and challenges enhancing goat production in East Africa. Processing of conference held at Debub University, Awassa, Ethiopia.

2. Abdissa A (2008) African plat form.

3. Agrawa BL (1996) Basic statistics. ( $3^{\text {rd }}$ edn), Newage Int p.1 limited publishers, New Delhi, India.

4. Ahmed M (2001) Raw hides and skin improvement in Ethiopia. A paper presented on a technical workshop on good practices for the Ethiopian hides and skin industry. Imperial Hotel conference Hall, Addis Ababa, Ethiopia.

5. Aiello SE, Mays A (1998) The Merck Veterinary manual. ( $8^{\text {th }}$ edn) NJ, Merck co Inc, white house station, USA.

6. Aiken ID (2007) Disease of sheep. ( $4^{\text {th }}$ edn) Edinburgh: Blackwell science Pp: 297-306.

7. Assegid BB (1991) Epidemiological study of major skin diseases of cattle. Addis Ababa University, Ethiopia.

8. Bishawired S (1991) Outbreak of lumpy skin disease in and around Wolliso. Addis Ababa University, Ethiopia.

9. Bradford P (1996) Large animal internal medicine ( $2^{\text {nd }}$ edn) St. Louis, Mosby year book Inc, USA.

10. Carton WW, Mc Gavin MD (1995) Special veterinary pathology. ( $\left.2^{\text {nd }} e d n\right)$ St. Lousi, Mosby year book Inc, USA.

11. Chalachew N (2001) Study on skin disease in cattle, sheep and goats in and around Wolayta Soddo, Southern Ethiopia. Addis Ababa University, Ethiopia.

12. Cottral GE (1978) Manual of standardized Methods for veterinary Microbiology. Comstic publishing associates a division of University press, USA.
13. CSA (2004) Central Statistical Authority. The 2001/02 Ethiopian Agricultural Sample Enumeration (ESAE), Executive Summary Ethiopia.

14. Dellmann HD, Eurell J (1998) Text book of veterinary Histology. $\left(5^{\text {th }}\right.$ edn $)$, USA pp: 303-311.

15. EBDSN (Ethiopian business development service Network) (2003) The Ethiopian leather and foot wear sector. available at.

16. Evans GO (1992) Principles of Acrology. CAB Internation Wallingford, UK. pp: $39-56$

17. Frandson RD, Wilke WL, Fasils AD (2003) Anatomy and physiology of farm animals. (6 ${ }^{\text {th }}$ edn) London, USA: Lippincott. Pp: 202-203.

18. Geremew T (1998) Prevalence of bovine dermatophilosis in and around Robe (Bale-Zone). Addis Ababa University, Ethiopia.

19. Gray P (1995) Parasites and skin diseases. J An Allen and company ltd London, UK.

20. Habte G (1994) The prevalence of mangemite infestation in camel, cattle and sheep in and around Mekele. Addis Ababa University, Ethiopia.

21. Hirsh DC, Zee YC (1999) Veterinary Microbiology. ( $4^{\text {th }}$ edn), Blackwell science, Britain, USA pp: 211-215.

22. Jungerman $P$ (1972) Veterinary medical Mycology. Philadelphia, USA.

23. Kassa B, Bisrat M, Asegedech S, Africa J (1998) Control of Ekek: skin defects in sheep by insecticide and shearing. Ethiopian Veterinary Association, proceedings $12^{\text {th }}$ annual conference. Addis Ababa, Ethiopia.

24. MAFF (Ministry of Agriculture, fisheries \& food) (1977) Manual of veterinary parasitological techniques. Technical bulletin No. $18 \mathrm{Her}$ Majesty's stationary office, UK.

25. Radostits OM, Blood DC, Gray CC (1994) Veterinary medicine: A text book of the diseases of cattle, sheep, pigs, goats and horses. $\left(8^{\text {th }}\right.$ edn $)$ Bailliere Tindall, UK.

26. Thrusfield M (1995) Veterinary Epidemiology. (2 $2^{\text {nd }}$ edn), Blackwell Science Ltd, Oxford pp. 296-311. 